\title{
Modeling and Evaluation of Multimodal Perceptual Quality
}

\author{
Petersen, Kim T; Hansen, Steffen Duus; Sørensen, John Aasted
}

Published in:

I E E E - Signal Processing Magazine

Link to article, DOI:

10.1109/79.598591

Publication date:

1997

Document Version

Publisher's PDF, also known as Version of record

Link back to DTU Orbit

Citation (APA):

Petersen, K. T., Hansen, S. D., \& Sørensen, J. A. (1997). Modeling and Evaluation of Multimodal Perceptual Quality. I E E E - Signal Processing Magazine, 14(4), 38-39. https://doi.org/10.1109/79.598591

\section{General rights}

Copyright and moral rights for the publications made accessible in the public portal are retained by the authors and/or other copyright owners and it is a condition of accessing publications that users recognise and abide by the legal requirements associated with these rights.

- Users may download and print one copy of any publication from the public portal for the purpose of private study or research.

- You may not further distribute the material or use it for any profit-making activity or commercial gain

- You may freely distribute the URL identifying the publication in the public portal

If you believe that this document breaches copyright please contact us providing details, and we will remove access to the work immediately and investigate your claim 
man perception of speech is bimodal in thal acoustic spech can be aftected by visual cues from lip movetnents. For example, one experiment shows that when a person "sees" a spedker say ing /ga/, but "hears" the sound bal, the person perceives neither /ga/ nor /ba/, but something close $10 / \mathrm{da} /$.

Due to the bimodality in speech perception, audiovisual interaction is an importani design factor for multimodal communication systems such as video telephony and video conferencing. A prime exaniple of this interaction is lip reading or specch reading. lip reading is not only used by the hearing-inpaired for speech understanding. In fact, creryone utilizes lip reading to some extent, in particular in a noisy environment such as at a cocktail party. Communication systems must be able to provide the lull motion necessatry for speech reading by the heariug-impaircd. Researches have studied the importance of frame rates with impared listeiers [2] anid analyzed the effects of lirame rates on troluted viseme recognition [3]. Research in these areas witlead to tiultimedia systems that account for the jerceptrat boundaries of the hearing-impaired. Researchers have also tried to teach computers to lip-read 15 . Based on comaputer-vision rechniques for tracking lip movements of a speaking person, a computer can be trained to underständ visuat speech. In addition, automatic lip reading has also been used to enhance acoustic speech recognition:

What can one do if the frame rate is not adequate for lip stnchronization perception. which is a typical situation in video conferencing equipment due to the bandwidth constraint? (ne solution is to extract the information fromthe acoustic signal that determines the corresponding mouth movements, and then process the speaker s mouth inage accordingly to achieve lip synctrontzation [4y. On the other hand, it is also possible to warp the acoustic signal to synchronize with the person's mouth moverients. The lat ter approach is very useful in nonreal-time applications, sucl as dubbing in a studio.

One key issue in binodal spech andy sis cund synthesis is the establishment of the mapping betwecn acoustic parameters and the mouth shape parameters fiother words, given the acoustic parameters, such as the cepstral coefficients, one needs to estimate the corresponding mouth shape and vice rersa. I number of approuches have becn proposed for this ask that utitize veclor ruantization [7]; neural neworks [8], Gaussian mixitures, and hidden Markol models [9].

Audio-visual interacion can be exploited in many other was. The correlation between audio and video can be utilized to achieve more efficient coding of both audio and rideo $[6,7]$. Audio-risual interaction can also be used for person authentication and verification $[10,11,12]$. Other applications include lubbing of moviès, seginentaron of image sequences using video and audio sigials [13], human-computer intertaces, and cartoon animation.
Alt these clearty demonstrate that the joint processing of audiand video proyides additional capabilities that are not possible when audio and video are studied separately. tit is clear that once we break down the arificial boundary berwe audio/specli and image/video processing, many inew researeh opportinities and innovative applications witl anise.

\section{Réferences}

1. MoGtirk and J.MacDonald; "Heariag lips and seeing voices," vaiure pp $746-748$ Decerabci 1970.

2. Frowein, et a "inproved spoch recognition through videocleph.

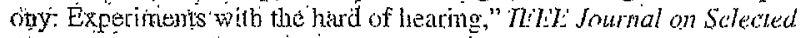

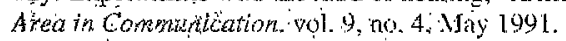

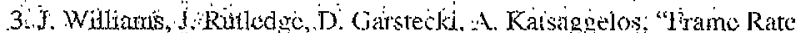
and Visene Aualysis For Multimedia Applications." Proc of IEEE VhI athacdia and Signal Processing Conlerenca, Princeton, NI. June 1997.

4. T. Chen, He Graf, and K. Wang, "Lip-synchromization using spoech-disisted ytdeo piocessing." IEE E Siginal Processing Lenter, vol. 2 , no A,pp: $57-59$, April 1995 .

5D. Stok thould see your lips move" HAJ and Specthreading:" HAL LEgacy. The M2' press 1997 .

6D. Stiah, and S Marshall, Multi-modality coding systein lor vidiophone applicanon WLASIC 94, Berljn, Germany, Oetober 1994.

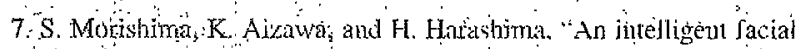
intage colling diven by speech and ploneme", IC LSSP, p. 1795; Glasgow, UK 1989

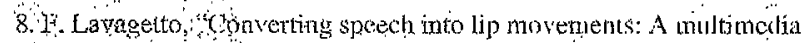
"telcphone tot hatd of hearing people." lEITK Trans. on Rehabilitation Einginceiting;pp it4, March 1995.

"1. Chen and $\mathrm{B}$ Kao, "Audjo $\checkmark$ isual Interacrom in Multimedia Comminicatton," vol, 1 .pp. (7) -182, ICASSP, Munich, April 1997.

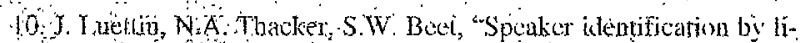
Eréding TCSPP, Ociober 1996.

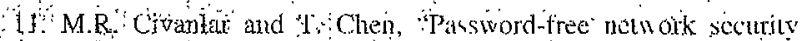
through joint use of andio and video," SPIT Photonio Fast November 1920.

12. Provedtings of the First iniemational confercnce on ficlio and Vide Biometric person duthemication, Cravis Montanal Swil/erland. March 122-14, Springer-Verlag, Berlin. 1997

13.J. Nain and AIr Tewhk, "Combined Audio and Visual Streans Adatysis for Video Sejucried Segmentation." ICAS'SP. Yol. + pp. 26652668, Munich, April 1997.

\section{Modeling and Evaluation of Multimodal Perceptual Quality}

Kim Tilgaard Petersen, Steffen Duns Haisen, John Aasled Surensen, Tech Cnitw of Denmark.

The inereasing perfurnance requitements of maltimedia nondalites, carrytng speech, audio, video, image, and graphics, emphasize the need for assessment methods of the lotal quality of a multimedia system and methods for sitizultarieous analysis of the sy stem components. It is important to take into account still more perceptual characteristics of the thuman auditory, visual, tactile systems, as well as combitations of these sxsterns. It is also highly desirable to acquire methods for andyzing the main perceptual parameters, which consitute the inpul for the total quality assessment. Atogether; this is necessary tor opti- 
mization of interacting modalities and the associated multimedia system transmission bandwidths. Examples of systems with interacting modalities are given in [2] and [3]. Today there is only little established consensus about methodologies for design and quality assessment of multimedia systems [3]. There is an increasing effort to incorporate perceptually important properties in the design and analysis of communication systems in general, as exemplified by [4] and [1].

In the following a framework is suggested for assessing the quality of modalities and their combinations. It is based on models for the total quality of given modalities logether with their perceptually important parameters. The models can either be based on two input signals consisting of a reference and its encoded/decoded representation, as exemplified in [1] for speech, or a single input signal just consisting of the latter one.

A quality model for a single modality (Fig. 3) can be structured in three layers. The first layer receives either the above two or one input signals and estimates, based on a perceptual model, a selection of parameters that can be used in the second layer for the estimation of the perceptually important parameters from which the total quality measure is derived in the third layer. A speech coding example of this model is given in [5]. Such models require design based on subjective tests and factor analysis.

In Fig. 4 a possible multimedia quality assessment model is shown, which delivers a selection of variables for audio- and video-system analysis. PVA/V are the perceptually most important variables for audio/video and TQA/V are the corresponding total quality of audio/video. All these are independent characterizations of audio/video.

The variables PVMMA/V describe the most important multimedia perceptual variables for audio and video. Accordingly, the measures TQMMA/V describe the total quality of audio/video, and finally TQMM describes the total quality of the multimedia system, taking into account simultaneous audio and video. The construction of such models represents substantial efforts, but this might be necessary to carry out simultaneous optimization of the modalities in multimedia systems.

\section{References}

1. J.G. Becrends. J.A. Stemcrdink, "A Perceptual Speech-Quality Measure Based on a Psychoacoustic Sound Representation." J. Audio Eng. Soc., vol. 42, no. 3. 1994 March.

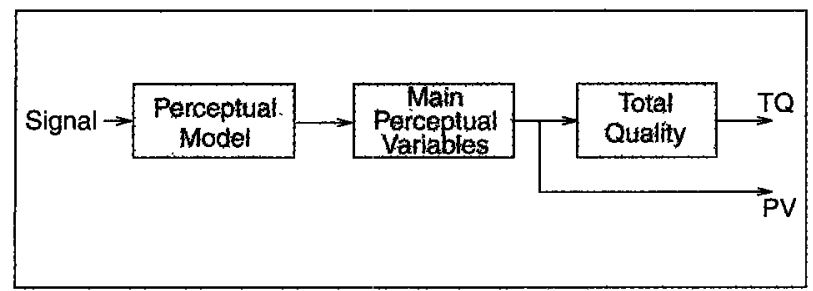

3. Three-layer quality model of a modality.

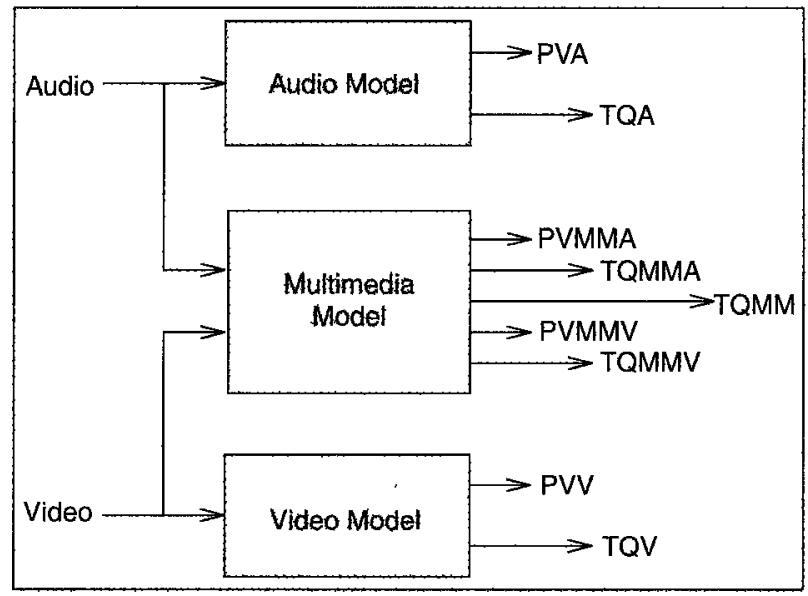

4. Multimedia quality assessment model.

2. T. Chen, R.R. Ran, "Audio-visual Interaction in Multimedia Communications," Proc: of 1997 Int. Conf. on Acoustics. Speech, and Signal Processing, vol. 1. pp. 179-182.

3. James Flanagan. Ivan Marsic, "Issues in Measuring the Benefits of Multimudal Interfaces," Proc. of 1997 Int. Conf. on Acoustics, Speech, and Signal Processing, vol. 1. pp. 163-166.

4. N. Jayant. I. Johnston. and R. Salranek, "Signal Compression Based on Models of Human Perception," Proc. of the IEEE, Oct. 1993. pp. 13851422 .

5. K.T. Pelersen, J.A. Sortensen, and S.D. Hansen, "Objective Speech Quality Assessment of Compounded Digital Telecommunication Systems." IEEE 1997 Workshop on Multimedia Signal Processing, Princeton. Junc 1997.

\section{Signal Processing for Networked Multimedia}

\section{Reha Civanlar and Amy Reibman, AT\&T Labs}

Real-time transmission of multimedia data over packet networks poses several interesting problems for signal processing research. Although the range of these problems covers a large variety of topics, currently two groups appear to attract the most attention. The first group concerns adapting the signal compression techniques to address the special requirements imposed by the packet networks, including accommodating for packet losses, delays, and jitter; providing capability for multipoint; and coping with the heterogeneous nature of today's networks. The second group of problems is related to protecting the intellectual property rights (IPRs) associated with the transmitted multimedia data. The increasing availability of highbandwidth networking makes it extremely easy to illegally duplicate and disseminate digital information. Unless a mechanism can be established to protect the rights of the content providers, commercial use of networked multimedia will remain extremely limited.

$\Lambda$ dapting signal compression techniques to networked applications may require some changes in the fundamental approach to this problem. The goal of classical signal compression is to achieve the highest possible compression ratio. The compression and transmission aspects have 